
\section{(dis)integrated development}

http:/ / doi.org/10.17648/ revistaterritorialidades-v1n2-7

\author{
Priscila Perelles \\ Universidade Tecnológica Federal do Paraná \\ E-mail: priperelles@gmail.com \\ Orcid: orcid.org/0000-0001-8650-5576
}

Ivan Carlos Vicentin Universidade Tecnológica Federal do Paraná E-mail: vicentin@utfpr.edu.br Orcid: orcid.org/0000-0002-7081-4005

Maria Meza Universidade Tecnológica Federal do Paraná E-mail: malumeza@utfpr.edu.br Orcid: orcid.org/0000-0002-1875-5140
Este artigo aborda o papel das cidades e do planejamento urbano para o desenvolvimento econômico e social e a importância das redes de cidades para impulsioná-lo. Os mecanismos legais atualmente existentes para promoção de desenvolvimento integrado das regiões metropolitanas no Brasil conflitam com o status quo das estruturas regionalizadas, gerando resistências à sua implantação. $\mathrm{O}$ estudo tem por objetivo identificar heterogeneidades no desenvolvimento dos municípios do Núcleo Urbano Central da Região Metropolitana de Curitiba e é delineado como estudo de caso múltiplo por método comparativo. O enfoque é descritivo dos dados de indicadores econômicos e sociais que foram coletados de bancos públicos de estatísticas. Os resultados apontam que a morosidade na elaboração do plano de desenvolvimento integrado e o acelerado crescimento da área urbana e das demandas por infraestrutura e serviços públicos perpetuam desigualdades socioeconômicas entre os municípios da região metropolitana de Curitiba.

Palavras-chave: Região metropolitana. Desenvolvimento urbano. Desigualdades.
ABSTRACT

This article approach the role of cities and urban planning roles for economic and social development and the importance of city networks to promote it. The legal mechanisms currently in place to promote the integrated development of metropolitan regions in Brazil conflict with the status quo of regionalized structures, generating resistance to their implementation. The study aims to identify heterogeneities in the development of the municipalities of the Central Urban Nucleus of the Metropolitan Region of Curitiba and is outlined as a multiple case study by comparative method. The focus is descriptive of the data on economic and social indicators that were collected from public statistical banks. The results show that the delay in preparing the integrated development plan and the accelerated growth of the urban area and the demands for infrastructure and public services perpetuate socio-economic inequalities between the municipalities of the metropolitan region of Curitiba.

Keywords: Metropolitan region. Urban development. Inequalities. 


\section{INTRODUÇÃO}

A expansão da urbanização desconhece os limites dos territórios políticoadministrativos estabelecidos. As demandas sociais por condições dignas de habitação, saneamento básico, educação, saúde e acesso ao emprego e renda da população que habita esses espaços urbanos são dirigidas ao Estado, independentemente da instância governamental à qual tenha sido convencionada a competência administrativa para atendê-las.

A existência de um ou vários focos urbanos com nível acentuado de autonomia é determinante na existência de heterogeneidades territoriais. Enquanto uns municípios possuem economias dinâmicas e diversificadas e alto padrão de vida, para outros a experiência é de estagnação econômica e condições de vida modestas ou precárias. A superação dessas disparidades ou a sua persistência depende do grau de fluidez física e institucional dos espaços econômicos e de certa homogeneidade socioeconômica entre os territórios. Sem essa coesão, a convergência para a integração econômica, que deveria ser geradora de oportunidades, pode se converter em relações de subordinação e não de equilíbrio (GONZALEZ, 2017).

A atual divisão político-administrativa da Federação brasileira descentraliza as questões urbanas nas escalas municipais, com estruturas sociais relativamente autônomas, as quais seriam motores para o desenvolvimento nacional, dinamizando empreendimentos comuns e a experiência de cidadania. Essa expectativa, no entanto, só seria válida naquelas localidades menores, onde a interação entre as classes sociais da comunidade é facilitada e todas recebem a mesma qualidade e quantidade de serviços públicos. A situação é mais complexa nos distritos pobres de grandes cidades, às quais se equiparam as regiões metropolitanas brasileiras (KAZTMAN, 2003).

O planejamento urbano voltado para o desenvolvimento integrado dos municípios de regiões metropolitanas se apresenta como ferramenta para promover a interação social, a cidadania e o desenvolvimento econômico pela soma de capital humano, das especializações e recursos deste e daquele território em prol da coletividade. No entanto, nas últimas décadas, o planejamento urbano tem sido atrasado pela ineficiência dos marcos institucionais vigentes. A Comissão Econômica para a America Latina e o Caribe (CEPAL) aponta para a necessidade de que seja implantada governança complexa das cidades e dos sistemas metropolitanos com instrumentos de planejamento urbano que sejam capazes de coordenar os diversos níveis de governo e também a relação destes com a sociedade civil e o setor privado (CEPAL, 2016).

A "expansão das cidades para muito além dos limites políticos administrativos que as nomearam no passado e a proposição de ações integradoras para realidades que são fragmentadas institucionalmente" (FREITAS-FIRKOWSKI, 2015, p. 17) é o desafio que o Estatuto da Metrópole propôs superar, prevendo diretrizes para o Plano de Desenvolvimento Urbano Integrado (PDUI) e instrumentos de governança interfederativa. Ocorre, porém, que as regiões metropolitanas hoje existentes no país foram constituídas muito antes da promulgação do Estatuto da Metrópole e as estruturas políticas e administrativas arraigadas têm se mostrado relutantes à adoção dos instrumentos legais para governança complexa.

O presente artigo tem o objetivo de investigar as desigualdades entre os municípios da Região Metropolitana de Curitiba (RMC) que a ausência de planejamento do desenvolvimento urbano integrado e da governança metropolitana produz ou perpetua. O estudo divide-se em oito capítulos, sendo este primeiro dedicado à introdução e o segundo à metodologia da pesquisa realizada. O terceiro capítulo discute o papel da urbanização e da gestão municipal no desenvolvimento, o Estatuto da Metrópole e o recente revés ocorrido pela revogação e alteração de seus imperativos normativos. O quarto capítulo traz o resgate histórico de formação da RMC e o quinto discute o Plano de Desenvolvimento Integrado (PDI) aprovado em 2006 pela Coordenação da Região Metropolitana de Curitiba (COMEC). No sexto capítulo são apresentados os indicadores de desenvolvimento econômico das cidades que compõem o 
chamado Núcleo Urbano Central (NUC) e, no sétimo, os indicadores sociais entre esses municípios. O último capítulo é dedicado às considerações finais.

\section{METODOLOGIA}

O objeto do estudo são fenômenos contemporâneos de desenvolvimento econômico e desigualdades entre diferentes municípios integrantes da RMC. A pesquisa é delineada como estudo de caso múltiplo, dado que objetiva proporcionar vivência da realidade por meio da discussão, análise e tentativa de solução de um problema extraído da vida real (CRESWELL, 2010; GODOY, 1995). O enfoque adotado é descritivo e utiliza o método comparativo para apurar similitudes e divergências entre os elementos da amostra em relação às variáveis selecionadas (MARCONI; LAKATOS, 2017), quais sejam, os indicadores econômicos ${ }^{1}$ e sociais ${ }^{2}$ dos municípios que compõem oNUC.

A coleta de dados foi realizada por documentação direta em bancos de dados públicos, precisamente no Banco de Tabelas Estatísticas SIDRA do Instituto Brasileiro de Geografia e Estatística (IBGE) e no sítio eletrônico do Instituto Paranaense de Desenvolvimento Econômico e Social (IPARDES). A pesquisa é delimitada aos 14 municípios que integram o NUC por serem estes que demandam, em razão da mancha de urbanização, a maioria das funções públicas de interesse comum e recebem mais direta e reciprocamente o impacto do planejamento urbano uns dos outros. Foi realizado, também, o recorte de tempo entre os anos de 2011 e 2016, em razão da disponibilidade de séries de dados municipais anuais para avaliação comparativa de indicadores econômicos e sociais.

\section{O ESTATUTO DA METRÓPOLE E O DESENVOLVIMENTO URBANO INTEGRADO DE REGIÕES METROPOLITANAS NO BRASIL}

As cidades têm elevado peso econômico e populacional que, associados à consolidação urbana, tem duas implicações fundamentais. A primeira, diz respeito ao relacionamento positivo da urbanização e do desenvolvimento urbano com o desenvolvimento econômico e a melhoria das condições de vida que, em última análise, resultam em desenvolvimento nacional. A segunda, que o desenvolvimento urbano sustentável e as políticas urbanas são instrumentos potencializadores das vantagens da urbanização e determinantes para a sustentabilidade na América Latina (CEPAL, 2016). Tanto economistas quanto urbanistas, há muito, observam a conexão existente entre a urbanização e o desenvolvimento econômico nacional e global. Porém, esta conexão tem sido enfraquecida e a tendência atual é a chamada "urbanização sem crescimento" (FLORIDA, 2016, p. 16).

As políticas habitacionais, as normas de parcelamento e uso de solo e os investimentos em infraestrutura urbana são fatores determinantes do valor imobiliário da propriedade privada. Se não forem bem geridos, provocam a segregação da população mais pobre em espaços desprovidos de infraestrutura, distantes das oportunidades da vida urbana, aumentam o custo e tempo de deslocamento e reduzem a qualidade de vida da população mais carente de atenção do poder público. Por isso, um dos maiores desafios urbanos da atualidade na América Latina são os baixos investimentos em infraestrutura urbana, o que implica consequências negativas na competitividade econômica, no acesso ao emprego e renda, no acesso aos serviços básicos e na qualidade de vida da população (CEPAL, 2016).

No Brasil, a rápida transição rural-urbana trouxe grande expansão das áreas urbanas. Porém, o tecido urbano formado e a gestão dos serviços públicos nem sempre coincidem com os limites político-administrativos da autonomia conferida a cada município. A conurbação dos espaços urbanos torna interdependente o planejamento e a gestão dos municípios, sobrepondo

\footnotetext{
1 Produto Interno Bruto - PIB e PIB per capita.

2 Índice IPARDES de Desenvolvimento Municipal - IPDM e Índice de Desenvolvimento Humano Municipal - IDHM.
} 
vários níveis de governo. A criação de regiões metropolitanas para gerir assuntos de interesse comum enfrenta, portanto, desafios de coordenação política e financeira entre os municípios para corrigir assimetrias da capacidade de gestão e de compilação de dados urbanos entre cidades de diferentes portes e necessidades (CEPAL, 2016; FREITAS-FIRKOWSKI, 2015).

No entanto, a dimensão metropolitana é, em geral, pouco considerada nos planejamentos urbanos municipais. Os planos diretores das cidades são elaborados como instâncias independentes e tratam as questões metropolitanas apenas de forma genérica, sem ações específicas para garantir sua implementação. Essa omissão legislativa se reflete em elevada carga discricionária e política do poder público para gerir a escala metropolitana (GORSDORF, 2009); postura que se opõe à função que se espera da região metropolitana de buscar soluções conjuntas para que todos os municípios integrantes alcancem o desenvolvimento sustentável, a superação da pobreza e das desigualdades.

A existência de um sistema de coordenação de atores políticos de diferentes instâncias locais, em conjunto com as instâncias políticas estadual e federal e os atores sociais e o mercado, é condição potencializadora para que a região metropolitana desfrute das vantagens de natureza cumulativa das economias de aglomeração. Sanfelici , apresenta as quatro principais vantagens da aglomeração: i) compartilhamento de infraestruturas físicas indivisíveis de alto custo; ii) interdependências de transações entre empresas de um segmento ou da mesma cadeia produtiva; iii) formação de mercado de trabalho denso, diversificado e especializado; iv) criação de ambiente favorável ao aprendizado e à inovação. A força centrípeta de aglomeração que as economias exercem acelera os processos de urbanização e, portanto, as questões urbanas e a urbanização precisam integrar o centro das discussões e das decisões públicas sobre desenvolvimento econômico e social despertando, inclusive na escala regional, o potencial latente de coordenação dos agentes públicos e, igualmente, dos agentes privados para alcançálo.

A Lei Federal n 13.089 , de 12 de janeiro de 2015, instituiu o Estatuto da Metrópole e criou um sistema de normas gerais para que fossem elaborados planos de desenvolvimento urbano integrado dos municípios das regiões metropolitanas. Foram previstos, também, instrumentos de governança interfederativa para viabilizar e legitimar o planejamento e o processo decisório quanto aos assuntos afetos à coletividade de municípios.

A norma federal exigia que, no prazo de três anos, contados da sua promulgação, fossem aprovadas leis complementares estaduais definindo o Plano de Desenvolvimento Urbano Integrado (PDUI), abrangendo todo o conjunto de municípios agrupados, considerando as áreas rurais e urbanas, e contendo, no mínimo:

I - diretrizes para as funções públicas de interesse comum, incluindo projetos estratégicos e ações prioritárias para investimentos;

II - o macrozoneamento da unidade territorial urbana;

III - as diretrizes quanto à articulação dos Municípios no parcelamento, uso e ocupação no solo urbano;

IV - as diretrizes quanto à articulação intersetorial das políticas públicas afetas à unidade territorial urbana;

V - a delimitação das áreas com restrições à urbanização visando à proteção do patrimônio ambiental ou cultural, bem como das áreas sujeitas a controle especial pelo risco de desastres naturais, se existirem;

VI - o sistema de acompanhamento e controle de suas disposições;

VII - as diretrizes mínimas para implementação de efetiva política pública de regularização fundiária urbana. (BRASIL, 2015).

Para elaboração do PDUI, o controle, a transparência e publicidade, assim como a participação popular seriam obrigatórios. A participação da população e da sociedade civil foi assegurada por audiências públicas a serem realizadas em todos os municípios da unidade 
territorial urbana. Nessa perspectiva participativa e integrada, o Estatuto da Metrópole também instrumentalizou a governança interfederativa para conferir autoridade e cogência às decisões públicas tomadas no âmbito do colegiado de municípios. O engajamento dos gestores municipais seria estimulado pela participação ativa de representantes do Poder Executivo de todos os entes federativos integrantes nas decisões metropolitanas, bem como pela alocação de recursos para financiamento e execução das funções públicas de interesse comum. A estrutura básica dessa governança interfederativa prevista em lei é a seguinte:

I - instância executiva composta pelos representantes do Poder Executivo dos entes federativos integrantes das unidades territoriais urbanas;

II - instância colegiada deliberativa com representação da sociedade civil;

III - organização pública com funções técnico-consultivas; e

IV - sistema integrado de alocação de recursos e de prestação de contas. (BRASIL, 2015).

Uma vez formalizada e delimitada a região metropolitana por lei complementar estadual, caso adotados os instrumentos de governança interfederativa e aprovado o plano de desenvolvimento urbano integrado, a unidade federativa metropolitana assumiria a condição de "gestão plena" prevista no Estatuto da Metrópole, que a habilita para receber apoio financeiro proveniente do orçamento da União. A norma federal preconiza, ainda, a cooperação entre os municípios corresponsáveis por funções públicas para promover o desenvolvimento recíproco. As regiões metropolitanas, geridas por mecanismos de governança interfederativa, devem funcionar como instrumento de ação de políticas públicas voltadas tanto para maximizar os efeitos positivos quanto para minimizar aqueles negativos.

As regiões metropolitanas, tanto nas relações com os municípios integrantes quanto nas relações com as demais regiões e o país, precisam ser consideradas como interligadas e subordinadas à concepção nacional do bem comum. Para tanto, os arranjos políticos, institucionais, administrativos e financeiros precisam ser articulados pela cooperação entre as três esferas de governo incluindo, em governança de múltiplo nível, o setor privado e os diversos segmentos da sociedade civil, onde se multiplicam os interesses econômicos, sociais e políticos em disputa (SOUZA, 2003).

A ausência de uma agenda interescalar coordenada na formulação e implementação de políticas públicas urbanas tem como consequência uma variada sorte de disfuncionalidades e ineficiências que impedem avanços no desenvolvimento urbano. A título exemplificativo, registra-se a contraposição entre os esforços empreendimentos pelos governos locais e estaduais no sistema de transporte coletivo e os incentivos federais ao transporte individual motorizado. Todavia, a construção de vínculos entre as escalas políticas não é uma questão meramente técnica, dado que envolve relações de poder e o fortalecimento de uma cultura de participação cidadã e democrática (SANFELICI, 2016).

De fato, o ordenamento jurídico reconhece que o crescimento harmonioso só pode ser alcançado através da coesão, da complementaridade e da cooperação entre as partes interessadas. Esses instrumentos legais para formulação da agenda regional metropolitana voltada para o desenvolvimento integrado conflitam, no entanto, com as estruturas e concepções pré-existentes nas regiões metropolitanas já instituídas no país, como a RMC criada em 1973.

\section{A FORMAÇÃO DA REGIÃO METROPOLITANA DE CURITIBA}

A RMC, inicialmente composta por 14 municípios $^{3}$, foi criada pela Lei Complementar Federal $n^{\circ} 14$, de 08 de junho de 1973, sob égide da ordem constitucional da Emenda $n^{\circ}$ 01, de 17

\footnotetext{
3 Curitiba, Almirante Tamandaré, Araucária, Bocaiúva do Sul, Campo Largo, Colombo, Contenda, Piraquara, São José dos Pinhais, Rio Branco do Sul, Campina Grande do Sul, Quatro Barras, Mandirituba e Balsa Nova.
} 
de outubro de 1969, juntamente com as regiões metropolitanas de São Paulo, Belo Horizonte, Porto Alegre, Recife, Salvador, Belém e Fortaleza, como resposta do governo federal à acelerada urbanização.

A criação dessas regiões metropolitanas foi orientada pelo artigo 164 da Emenda Constitucional $\mathrm{n}^{\circ} 01$ - conhecida como "Constituição de 1969" - que preconizava o reconhecimento de comunidades socioeconômicas entre municípios, independentemente de vinculação administrativa entre eles. A ordem então vigente havia excluído do texto constitucional o objetivo de realização de serviços de interesse comum que constava na redação original do $\$ 10$ do artigo 157 da Constituição Federal de 1967.

A primeira experiência brasileira de metropolização, no início dos anos 70, ficou marcada, então, pelo contexto político de autoritarismo e de centralização do regime ditatorial do governo militar, que desconsiderava o sistema democrático, o federalismo e as relações intergovernamentais e almejava, pela criação de regiões metropolitanas, a extensão de braços do governo federal. Essa formatação inicial das regiões metropolitanas com centralização em unidades gestoras, avessa aos mecanismos de cooperação e de governança metropolitana, e dissociada de um senso de identidade regional, ainda repercute na atualidade como efeito de uma path dependency (rota dependente), ou increasing returns (retornos recentes), ou seja: os elevados custos da mudança de trajetória mantêm uma cadeia de causalidade de decisões passadas que influenciam as decisões no presente (SOUZA, 2003).

Com a promulgação da Constituição Federal de 1988, a competência para, mediante lei complementar, criar, alterar e extinguir regiões metropolitanas foi deslocada para os estadosmembros e os municípios ganharam autonomia em relação aos estados para editar suas próprias leis orgânicas. A formação das regiões passou a ser orientada pelo agrupamento de municípios limítrofes para integrar a organização, o planejamento e a execução de funções públicas de interesse comum, como previsto no $\$ 3^{\circ}$ do artigo 25 da Constituição, e não mais exclusivamente pelos interesses socioeconômicos.

Esse momento de redemocratização representou importante momento crítico (critical juncture) para mudança do paradigma autoritário e centralizador inicial, notadamente pela saliência dos governos subnacionais no processo de reestruturação democrática e pela partilha do poder territorial em três esferas. No entanto, não obstante tenha sido repartida com os estados e municípios a competência administrativa para gerir políticas públicas e a arrecadação financeira do Estado, a federação brasileira instituída pela Constituição de 1988 é marcada pela hegemonia da União nas decisões públicas, em razão da concentração/monopólio das competências legislativas na escala federal, limitando a capacidade dos estados e dos municípios de gerirem políticas próprias, ocasionando desequilíbrios, conflitos e pontos de tensão federativa. Estes desequilíbrios são estampados nas regiões metropolitanas onde se encontram as três esferas autônomas de governo e se expressa a grande interdependência política e tributária que, enfim, resulta na preponderância do peso político, financeiro e populacional de uns municípios sobre os outros, já que o constituinte, apesar de entregar uma constituição programática em inúmeros aspectos, não criou, de imediato, os mecanismos de cooperação ou indicou os recursos financeiros específicos para as demandas metropolitanas, que passaram a ser tratadas ora como questão estadual ora municipal (SOUZA, 2003).

Na formação da RMC, a transferência do poder normativo para a esfera estadual, associada ao processo de intenso desmembramento de municípios no período, inflou a região nos anos seguintes à promulgação da Constituição. Entre os anos de 1994 e 2011, foram aprovadas cinco leis estaduais, dobrando o número de municípios agrupados na região metropolitana. Atualmente são 29 os municípios que integram a $\mathrm{RMC}^{4}$, que abrange área total de $15.418,6 \mathrm{~km}^{2}$, sendo a quarta maior região metropolitana em área de extensão.

\footnotetext{
4 A Lei Estadual n 11.027/1994 adicionou oito municípios: Cerro Azul, Dr. Ulysses, Itaperuçu, Fazenda Rio Grande, Pinhais, Quitandinha, Tijucas doSul e Tunas do Paraná.
} 
A densidade demográfica, porém, é de 205,87 habitante $/ \mathrm{km}^{2}$, o que a classifica em $19^{\circ}$ lugar dentre as 36 regiões metropolitanas estabelecidas no país (IBGE, 2010a). A população total da RMC registrada no Censo de 2010 é de 3.174.201 pessoas e, destas, apenas 252.356 pessoas residem em área rural, o que resulta em um percentual de $92 \%$ de população urbana (IBGE, 2010b).

A mancha urbanizada concentrada no entorno próximo da cidade polo, Curitiba, destaca um grupo de municípios conhecido como Núcleo Urbano Central (NUC). Esse Núcleo é formado por 14 municípios: Almirante Tamandaré, Araucária, Campina Grande do Sul, Campo Largo, Campo Magro, Colombo, Curitiba, Fazenda Rio Grande, Itaperuçu, Pinhais, Piraquara, Quatro Barras, Rio Branco do Sul eSão José dos Pinhais.

De acordo com o último Censo Demográfico (IBGE, 2010b), a população total do NUC é de 2.892.541 pessoas, sendo 95\% delas com domicílios urbanos e apenas $5 \%$ rurais. As cidades de Curitiba e Pinhais registram população integralmente absorvida em domicílios da área urbana e, apenas nos municípios de Almirante Tamandaré e Piraquara, o percentual de população em domicílios de área rural é superior à urbana. A cidade de Rio Branco do Sul destaca-se pelo percentual mais elevado de população domiciliada em área rural (28\%) dentre aquelas predominantemente urbanas. O gráfico 1 ilustra a situação de domicílios urbanos e rurais nas cidades que integram o NUC.

Gráfico 1 - População residente, por situação do domicílio, no NUC. Referência 2010

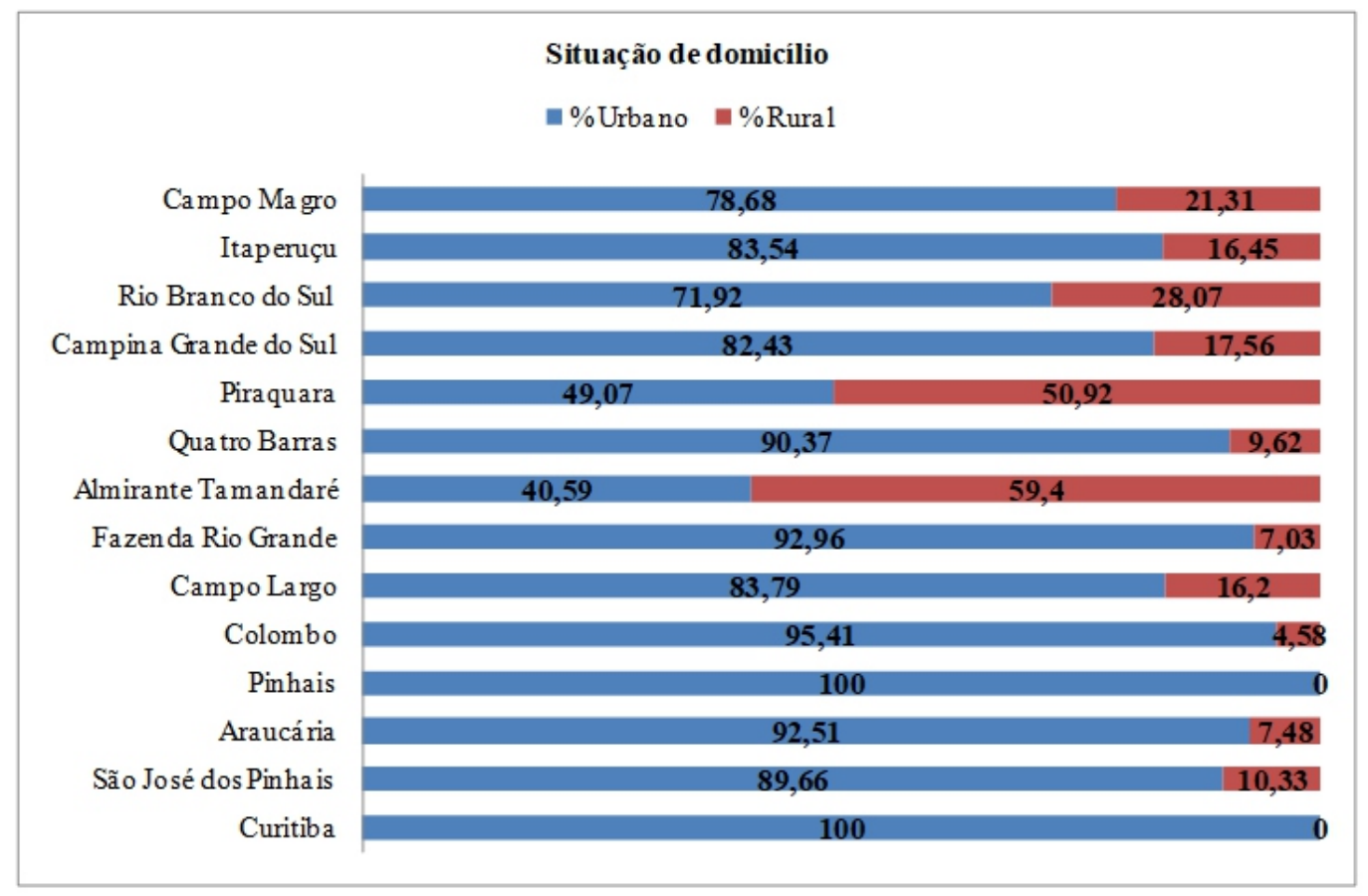

Fonte: IIBGE, 2010b. Elaborado pelos autores.

Em geral, a população rural tende a ser maior nas cidades com menos de 20 mil habitantes, representando um terço nas cidades entre 20 e 50 mil habitantes. A proporção rural decresce quanto maior a população do município e nas grandes cidades se concentra a pobreza em termos absolutos (AZEREDO; LOBO, 2004). Na RMC, no entanto, as restrições do planejamento urbano de Curitiba e a facilidade de aquisição de moradia nas cidades do entorno causaram o transbordamento dos limites administrativos da capital e expansão da ocupação metropolitana

A Lei Estadual nº 11.096/1995 adicionou dois municípios: Adrianópolis, Campo Magro.

A Lei Estadual n 12.125/1998 adicionou um município: Agudos do Sul,

A Lei Estadual $n^{\circ} 13.512 / 2002$ adicionou um municípios: Lapa.

A Lei Complementar Estadual $n^{\circ}$ 139/ 2011 adicionou três municípios: Campo do Tenente, Piên e Rio Negro. 
a partir dos anos 90 (GORSDORF, 2009). O adensamento populacional e a conurbação das cidades do NUC as tornaram suscetíveis à urbanização e às desigualdades dela derivadas, em detrimento da ruralidade, mesmo naquelas cidades com populações inferiores a 20 mil habitantes.

Essa conurbação torna os municípios do NUC mais compatíveis com os objetivos de organização, planejamento e execução de funções públicas de interesse comum, na forma atualmente prevista na Constituição Federal, do que outras cidades que integram a RMC (FREITAS-FIRKOWSKI, 2015). No NUC também são mais significativos os impactos do desenvolvimento urbano e suas consequências positivas e negativas, inclusive em relação aos espaços rurais que já se apresentam comprimidos pelo avanço da mancha urbanizada.

\section{PLANO DE DESENVOLVIMENTO INTEGRADO DA REGIÃO METROPOLITANA DE CURITIBA}

O $\S 3^{\circ}$ do artigo 25 da Constituição Federal de 1988 dispõe que as regiões metropolitanas devem ser estabelecidas por agrupamentos de municípios limítrofes para organização, planejamento e execução de funções públicas de interesse comum. Este dispositivo, porém, só veio a ser efetivamente regulamentado pelo Estatuto da Metrópole em 2015, 27 anos depois da promulgação da Constituição.

Apenas, então, passou a ser definido o conceito legal de função pública de interesse comum que deveria orientar a formação de regiões metropolitanas. A função pública de interesse comum, de acordo com o inciso II do artigo $2^{\circ}$ do Estatuto da Metrópole, é conceituada como "política pública ou ação nela inserida cuja realização por parte de um Município, isoladamente, seja inviável ou cause impacto em Municípios limítrofes" (BRASIL, 2015, s.p.).

No entanto, como já exposto, a formação da RMC é anterior à ordem constitucional ora vigente. A Lei Complementar Federal no 14, de 08 de junho de 1973, que a instituiu, determinou, em seu artigo $2^{\circ}$, que as questões metropolitanas fossem gerenciadas por um Conselho Deliberativo, presidido pelo governador do estado e composto de cinco membros de reconhecida capacidade técnica ou administrativa por ele nomeados. Nesse modelo gerencial apenas dois dos membros seriam indicados pelos municípios integrantes, um pela capital e outro pelos demais. A participação de todos os municípios era garantida apenas no Conselho Consultivo, sem poder decisório.

Seguindo esse molde, a Lei Estadual n ${ }^{\circ} 6.517$, de 02 de janeiro de 1974, criou a Coordenação da Região Metropolitana de Curitiba (COMEC), como órgão dotado de autonomia técnica e administrativa vinculado ao governo estadual, com estrutura deliberativa e consultiva e atribuições definidas na lei federal. Pela Lei Estadual no 11.027, de 29 de dezembro de 1994, foi alterada a personalidade jurídica do órgão metropolitano, que passou a integrar a administração pública indireta sob a forma de autarquia, com autonomia administrativa, financeira e patrimonial, mantida a sua organização deliberativa e consultiva e, também, a vinculação à secretaria estadual. Por força do Decreto Estadual n 6384, de 04 de abril de 2006, a COMEC é, atualmente, vinculada à Secretaria de Estado do Desenvolvimento Urbano (SEDU).

Este é o escopo normativo ainda vigente que rege a gestão metropolitana da região de Curitiba. Nestas condições de gestão, sob forte gerência do governo estadual e hegemonia da capital, a COMEC aprovou, em 2006, o Plano de Desenvolvimento Integrado (PDI) da RMC (COMEC, 2006) revisando o primeiro plano de planejamento institucionalizado realizado em 1978. O PDI 2006 apresentou-se como tentativa de superar as dificuldades de gestão já identificadas desde os anos 2000. Baseado em análise de cenário metropolitano, porém, limitou-se a propor planejamento de ordenamento territorial e definir apenas duas linhas estratégicas de ação: i) proteção, conservação e preservação do meio ambiente; ii) ordenamento da expansão e crescimento urbano.

Apesar de haver sido previsto processo de participação popular em sua elaboração, não houve continuidade desse propósito e o plano foi construído intramuros, por uma equipe técnica 
designada. Desde logo, portanto, foi mitigada a legitimidade e a efetividade das propostas de políticas públicas ali formuladas. O PDI enfrentou, ainda, variada sorte de desafios: questões político-partidárias; descontinuidade de governos; falta de integração dos entes responsáveis pelas políticas públicas; desigualdades entre os municípios no processo decisório metropolitano; hegemonia da capital; e ausência de instrumentos para integração (GORSDORF, 2009).

Os entraves já eram reconhecidos pelo próprio PDI, que propôs reformulação do modelo institucional de gestão metropolitana, destacando três ordens de obstáculos à gestão metropolitana: i) de nível técnico, referentes aos aspectos estruturais da COMEC de quadros e capacitação técnica e instrumentos adequados; ii) de nível político, uma vez que as decisões metropolitanas são condicionadas em nível de engajamento da classe política e dos gestores do poder executivo; iii) de nível jurídico-administrativo, relacionados à legitimidade, às atribuições, competências e responsabilidades legais e à personalidade jurídica e estrutura organizacional (COMEC, 2006).

Sem demérito ao trabalho desenvolvido em 2006, após a aprovação do Estatuto da Metrópole, sua aplicação restou comprometida. Como reconhece o próprio documento, ao tempo de sua formulação não havia definição de função pública de interesse comum, conceito central dos objetivos das regiões metropolitanas (COMEC, 2006). Não havia previsão, também, de contribuição obrigatória ao financiamento da execução dessas funções pelos municípios, o que implicaria, inclusive, a reavaliação do interesse político-administrativo e dos custos e benefícios da participação de alguns municípios que integram a região metropolitana.

A revisão desse plano para adequar-se aos parâmetros do PDUI era medida obrigatória e aprazada pelo Estatuto da Metrópole. A lei, em seu artigo 21, tipificou como crime de improbidade administrativa a omissão do governo estadual em elaborar e aprovar o PDUI no prazo de três anos, que se encerraria em 12 de janeiro de 2018. No entanto, um dia antes do vencimento desse prazo, o Presidente da República editou a Medida Provisória no 818, de 11 de janeiro de 2018, alterando para cinco anos o prazo para elaboração e aprovação do PDUI, ou seja, deslocando a data limite para 12 de janeiro de 2021.

Apreciada no Congresso Nacional, a Medida Provisória foi convertida na Lei Federal $\mathrm{n}^{\circ}$ 13.683, de 19 de junho de 2018, e esmoreceu o projeto nacional de planejamento urbano integrado para desenvolvimento das regiões metropolitanas. O dispositivo do artigo 21, que previa o prazo para elaboração do PDUI e a responsabilização por improbidade administrativa, foi integralmente revogado e, no parágrafo único do artigo $2^{\circ}$ do Estatuto da Metrópole, foi atribuído aos colegiados metropolitanos já instituídos o poder de decidir pela sua adoção ou não.

Poucas regiões metropolitanas que já haviam se articulado para o cumprimento do prazo inicialmente previsto, avançaram e conseguiram concluir a etapa de elaboração do PDUI. No Relatório Anual de Avaliação do Plano Plurianual (PPA) do Governo Federal do ano-base de 2017, observa-se que apenas 1,25\% das regiões metropolitanas haviam avançado na adoção do PDUI, quando a meta do planejamento nacional era atingir $100 \%$ das regiões metropolitanas até $\mathrm{o}$ ano de 2019 (BRASIL, 2018).

Cite-se, como exemplo de avanço mais recente, o Conselho de Desenvolvimento da Região Metropolitana de São Paulo (CDRMSP) ${ }^{5}$ que aprovou, em 24 de abril de 2019, o PDUI para a metrópole, passando à fase legislativa de formação da lei estadual. Já a gestão da RMC, sob a coordenação da COMEC, pouco informa acerca da condução do processo de elaboração do PDUI. No portal eletrônico, a informação, sem data de referência, é de que o projeto ainda está em fase inicial, preparatória6.

\footnotetext{
${ }^{5}$ Disponível em https://www.pdui.sp.gov.br/rmsp/?p=12503 acesso em 06 out. 2019.

${ }^{6}$ Disponível em http:/ / www.comec.pr.gov.br/Pagina/Audiencias-Publicas-do-PDUI acesso em 08 out. 2020.
} 
Todavia, ante a ausência de obrigatoriedade de planejamento e de articulação por governança interfederativa, não seria surpresa que os interesses de grupos políticos venham a ser sobrepostos ao planejamento do desenvolvimento integrado, cooperativo e voltado para superação de desigualdades sociais que se esperava quando o Estatuto da Metrópole entrou em vigor. A ausência de um a consciência coletiva sobre a importância das questões metropolitanas para o desenvolvimento econômico e social, e de um senso de identidade regional resulta da experiência brasileira autoritária e impositiva da criação das regiões metropolitanas e se reflete, ainda hoje, em desinteresse tanto dos políticos eleitos quanto da própria sociedade e do setor privado na agenda metropolitana, com raras exceções, silenciada (SOUZA, 2003). A omissão na elaboração e aprovação do plano implica atrasos e oportunidades perdidas de avanço na direção do desenvolvimento integrado da RMC.

Registra-se que, apesar de haver previsão de integração e governança interfederativa, tanto no Estatuto da Metrópole quanto no Plano Diretor da cidade de Curitiba (Lei Municipal n ${ }^{\circ}$ 14.771, de 17 de dezembro de 2015), a ausência de um PDUI construído conjuntamente inviabiliza a efetiva e producente articulação entre os governos dos municípios que integram a RMC. O reflexo disso é que a capital, cidade polo que provoca os impactos mais relevantes na urbanização de toda a região, promulgou recentemente a Lei Municipal no 15.511, de10 de outubro de 2019, que constitui o novo marco normativo do zoneamento e uso do solo da cidade, gerando reflexos em toda estrutura econômica da região, sem que tenha sido discutido regionalmente com as demais instâncias de governança da metrópole. Isso denota que ainda são mantidas medidas urbanísticas que, desde a década de 90, sobrevalorizam o solo da capital, tornando-o seletivo e intensificando as diferenças econômico-sociais entre os municípios da metrópole (GORSDOLF, 2009), em detrimento do desenvolvimento integrado.

\section{INDICADORES ECONÔMICOS DE DESENVOLVIMENTO NO NÚCLEO URBANO CENTRAL}

Os dados de Produto Interno Bruto (PIB) dos municípios que integram o NUC no período selecionado para análise, de 2011 a 2016 (Quadro 1), demonstram, já em primeira análise, que não há homogeneidade de capacidade econômica entre todas as unidades. A cidade polo, Curitiba, ostenta o quinto maior PIB do país, de acordo com os valores apurados pelo IBGE em 2016. Já os municípios de Itaperuçu e Campo Magro colocam-se muito atrás neste ranking, na $1377^{\mathrm{a}}$ e $1638^{\mathrm{a}}$ posição, respectivamente, com PIB abaixo de quinhentos mil reais.

A diferença percentual entre as cidades do grupo com o maior e o menor PIB, Curitiba e Campo Magro, respectivamente, é de 99,57\% no ano de 2016. O PIB do município de Campo Magro equivale a apenas $0,42 \%$ do PIB de Curitiba. Mesmo quando comparado à segunda maior economia do grupo, São José dos Pinhais, o PIB de Campo Magro continua expressivamente menor, representando somente $1,76 \%$ daquele.

Dos 3.397.237 habitantes do NUC, 56,90\% residem em Curitiba, cuja área é totalmente urbana. Essa capital registrou PIB acima de 83 milhões de reais no ano de 2016, com crescimento de $21 \%$ em relação ao ano de 2011. Na cidade menos populosa da região, Quatro Barras, também majoritariamente urbana, o crescimento do PIB no mesmo período manteve patamar semelhante, de $26 \%$. Esse crescimento, porém, não é homogêneo no NUC (Quadro 1). As cidades de Araucária, que se recuperou de queda nos anos de 2012 e 2013, e de Fazenda Rio Grande registraram, em 2016, crescimento do PIB acima de 50\% em relação ao resultado de 2011. Em Colombo, Campo Largo e Almirante Tamandaré, o crescimento foi na ordem aproximada de $40 \%$. Já na cidade de Rio Branco do Sul, a variação do PIB entre 2011 e 2016 foi de apenas 12\% e São José dos Pinhais, distanciandose do grupo, teve o índice reduzido em $2,81 \%$.

Pela associação do indicador econômico de PIB com a medida populacional, tem-se o PIB per capita (Quadro 2). Na cidade menos populosa do NUC, Quatro Barras, o PIB per capita é de R\$ 55.692,28; ou seja, 20,56\% superior ao da cidade mais populosa, Curitiba, que tem PIB per capita 
de $\mathrm{R} \$ 44.239,20$. Nesse índice per capita a liderança isolada é da cidade de Araucária que registra expressivos R \$125.342,73 per capita. O PIB per capita de Araucária é 46,92\% superior ao segundo colocado, São José dos Pinhais, e 64,70\% superior ao da capital, que é a cidade polo da região. A disparidade é ainda mais significativa quando se compara o índice de Araucária com Piraquara, chegando-se à diferença de $91,49 \%$.

Quadro 1- Evolução do PIB a preços correntes (mil reais). Referência de 2011 a 2016

\begin{tabular}{|c|c|c|c|c|c|c|c|}
\hline Ranking* & Município/Ano & $\mathbf{2 0 1 1}$ & $\mathbf{2 0 1 2}$ & $\mathbf{2 0 1 3}$ & $\mathbf{2 0 1 4}$ & $\mathbf{2 0 1 5}$ & $\mathbf{2 0 1 6}$ \\
\hline $5^{\circ}$ & Curitiba (PR) & $\mathrm{R} \$ 65.924 .883,00$ & $\mathrm{R} \$ 70.637 .709,00$ & $\mathrm{R} \$ 79.767 .473,00$ & $\mathrm{R} \$ 81.198 .399,00$ & $\mathrm{R} \$ 83.856 .186,00$ & $\mathrm{R} \$ 83.788 .904,00$ \\
\hline $40^{\circ}$ & São José dos Pinhais (PR) & $\mathrm{R} \$ 20.709 .464,00$ & $\mathrm{R} \$ 22.271 .624,00$ & $\mathrm{R} \$ 25.207 .296,00$ & $\mathrm{R} \$ 22.736 .762,00$ & $\mathrm{R} \$ 22.807 .863,00$ & $\mathrm{R} \$ 20.142 .954,00$ \\
\hline $51^{\circ}$ & Araucária (PR) & $\mathrm{R} \$ 7.339 .632,00$ & $\mathrm{R} \$ 5.721 .493,00$ & $\mathrm{R} \$ 6.838 .315,00$ & $\mathrm{R} \$ 8.538 .137,00$ & $\mathrm{R} \$ 13.951 .904,00$ & $\mathrm{R} \$ 16.978 .801,00$ \\
\hline $167^{\circ}$ & Pinhais (PR) & $\mathrm{R} \$ 3.913 .013,00$ & $\mathrm{R} \$ 4.504 .340,00$ & $\mathrm{R} \$ 4.960 .197,00$ & $\mathrm{R} \$ 5.123 .002,00$ & $\mathrm{R} \$ 5.091 .340,00$ & $\mathrm{R} \$ 5.386 .570,00$ \\
\hline $198^{\circ}$ & Colombo (PR) & $\mathrm{R} \$ 2.762 .519,00$ & $\mathrm{R} \$ 3.265 .102,00$ & $\mathrm{R} \$ 3.792 .054,00$ & $\mathrm{R} \$ 4.273 .856,00$ & $\mathrm{R} \$ 4.393 .213,00$ & $\mathrm{R} \$ 4.671 .356,00$ \\
\hline $233^{\circ}$ & Campo Largo (PR) & $\mathrm{R} \$ 2.223 .542,00$ & $\mathrm{R} \$ 2.589 .934,00$ & $\mathrm{R} \$ 3.481 .891,00$ & $\mathrm{R} \$ 3.613 .868,00$ & $\mathrm{R} \$ 3.589 .719,00$ & $\mathrm{R} \$ 3.811 .584,00$ \\
\hline $404^{\circ}$ & Fazenda Rio Grande (PR) & $\mathrm{R} \$ 848.805,00$ & $\mathrm{R} \$ 968.330,00$ & $\mathrm{R} \$ 1.325 .511,00$ & $\mathrm{R} \$ 1.586 .646,00$ & $\mathrm{R} \$ 1.758 .886,00$ & $\mathrm{R} \$ 2.060 .463,00$ \\
\hline $553^{\circ}$ & Almirante Tamandaré (PR) & $\mathrm{R} \$ 835.029,00$ & $\mathrm{R} \$ 938.850,00$ & $\mathrm{R} \$ 1.101 .377,00$ & $\mathrm{R} \$ 1.215 .481,00$ & $\mathrm{R} \$ 1.260 .049,00$ & $\mathrm{R} \$ 1.396 .289,00$ \\
\hline $610^{\circ}$ & Quatro Barras (PR) & $\mathrm{R} \$ 917.650,00$ & $\mathrm{R} \$ 883.279,00$ & $\mathrm{R} \$ 1.545 .573,00$ & $\mathrm{R} \$ 1.133 .161,00$ & $\mathrm{R} \$ 1.163 .298,00$ & $\mathrm{R} \$ 1.244 .890,00$ \\
\hline $663^{\circ}$ & Piraquara (PR) & $\mathrm{R} \$ 772.102,00$ & $\mathrm{R} \$ 933.690,00$ & $\mathrm{R} \$ 1.083 .804,00$ & $\mathrm{R} \$ 1.121 .004,00$ & $\mathrm{R} \$ 1.064 .518,00$ & $\mathrm{R} \$ 1.133 .372,00$ \\
\hline $651^{\circ}$ & Campina Grande do Sul (PR) & $\mathrm{R} \$ 809.776,00$ & $\mathrm{R} \$ 889.605,00$ & $\mathrm{R} \$ 1.009 .675,00$ & $\mathrm{R} \$ 1.028 .828,00$ & $\mathrm{R} \$ 1.098 .862,00$ & $\mathrm{R} \$ 1.150 .997,00$ \\
\hline $689^{\circ}$ & Rio Branco do Su1(PR) & $\mathrm{R} \$ 941.132,00$ & $\mathrm{R} \$ 949.955,00$ & $\mathrm{R} \$ 1.018 .127,00$ & $\mathrm{R} \$ 1.209 .260,00$ & $\mathrm{R} \$ 1.174 .898,00$ & $\mathrm{R} \$ 1.074 .796,00$ \\
\hline $1377^{\circ}$ & Itaperuçu (PR) & $\mathrm{R} \$ 330.639,00$ & $\mathrm{R} \$ 395.105,00$ & $\mathrm{R} \$ 414.739,00$ & $\mathrm{R} \$ 432.708,00$ & $\mathrm{R} \$ 411.118,00$ & $\mathrm{R} \$ 452.457,00$ \\
\hline $1638^{\circ}$ & Campo Magro (PR) & $\mathrm{R} \$ 225.982,00$ & $\mathrm{R} \$ 254.466,00$ & $\mathrm{R} \$ 277.774,00$ & $\mathrm{R} \$ 292.746,00$ & $\mathrm{R} \$ 322.801,00$ & $\mathrm{R} \$ 356.409,00$ \\
\hline
\end{tabular}

Fonte: IBGE, [s.d]. Elaborado pelos autores.

Quadro 2 - PIB per capita, referência 2016, e população estimada, referência 2019

\begin{tabular}{|c|c|c|c|}
\hline$\#$ & Municipio & PIB per capita (2016) & População es timada (2019) \\
\hline $1^{\circ}$ & Araucária (PR) & R\$125.342,73 & 143.843 \\
\hline $2^{\circ}$ & São José dos Pinhais (PR) & RS66.531,31 & 323.340 \\
\hline $3^{\circ}$ & Quatro Barras (PR) & RS55.692,28 & 23.559 \\
\hline $4^{\circ}$ & Curitiba (PR) & RS44.239,20 & 1.933 .105 \\
\hline $5^{\circ}$ & Pinhais $(\mathrm{PR})$ & RS41.998,58 & 132.157 \\
\hline $6^{\circ}$ & Rio Branco do Sul (PR) & $\mathrm{R} \$ 33.204,48$ & 32.397 \\
\hline $7^{\circ}$ & Campo Largo (PR) & $\mathrm{R} \$ 30.318,28$ & 132.002 \\
\hline $8^{\circ}$ & Campina Grande do Sul (PR) & RS27.283,22 & 43.288 \\
\hline $9^{\circ}$ & Fazenda Rio Grande (PR) & R\$21.982,96 & 100.209 \\
\hline $10^{\circ}$ & Colombo (PR) & RS19.883,10 & 243.726 \\
\hline $11^{\circ}$ & Itaperu çu (PR) & RS16.676,75 & 28.634 \\
\hline $12^{\circ}$ & Campo Magro (PR) & $\mathrm{R} \$ 12.781,85$ & 29.318 \\
\hline $13^{\circ}$ & Almirante Taman daré (PR) & $\mathrm{R} \$ 12.234,31$ & 118.623 \\
\hline $14^{\circ}$ & Piraquara (PR) & $\mathrm{R} \$ 10.678,89$ & 113.036 \\
\hline
\end{tabular}

Fonte: IBGE, 2010b; IBGE, 2019. Elaborado pelos autores.

A capital exerce forte atratividade de população e impulsiona a difusão espacial por contiguidade, com sistema de economias de aglomeração (LIMA, BIDARA, 2019). Apesar de possuir o setor industrial mais desenvolvido do grupo, a alta concentração populacional reverte-se em índice per capita reduzidos em relação às cidades vizinhas, que também possuem indústrias expressivas como a Refinaria do Paraná (REPAR) em Araucária e a indústria automobilística em São José dos Pinhais, localidades com população bastante menor que a capital.

Esses indicadores demonstram que há heterogeneidades significativas de crescimento econômico entre os centros urbanos que estão coligados em região metropolitana. A cidade polo, Curitiba, concentra riquezas e também a densidade populacional do NUC. Nas cidades 
limítrofes de Araucária e São José dos Pinhais, a indústria se desenvolveu sem a mesma concentração populacional em seus centros urbanos. Por outro lado, integram o NUC cidades com realidades econômicas e populacionais muito diversas, como as cidades de Itaperuçu e Campo Magro, que têm baixo desempenho tanto no PIB absoluto quanto no PIB per capita. Essa falta de homogeneidade econômico-social e planejamento para o desenvolvimento integrado se reverte em desigualdades sociais, tema abordado na próxima seção.

\section{INDICADORES ECONÔMICOS DE DESENVOLVIMENTO NO NÚCLEO URBANO CENTRAL}

O Instituto Paranaense de Desenvolvimento Econômico e Social (IPARDES) é órgão de pesquisa vinculada à Secretaria de Estado do Planejamento e Projetos Estruturantes (SEPL), cuja função é estudar a realidade econômica e social do Estado para subsidiar a formulação, a execução, o acompanhamento e a avaliação de políticas públicas. O Instituto desenvolveu o Índice de Desempenho Municipal (IPDM) para avaliar três dimensões de desenvolvimento: i) renda, emprego e produção agropecuária; ii) saúde e iii) educação. A base de dados utilizada para compor o IPDM são as estatísticas oficiais disponíveis publicamente com periodicidade anual.

Em recorte temporal idêntico àquele utilizado para avaliar a evolução do PIB dos municípios do NUC, o quadro abaixo demonstra a evolução do desempenho dos municípios nas dimensões de desenvolvimento que vão além do mero crescimento econômico. Nessa avaliação comparativa (Quadro 3), percebe-se que o município que obteve melhora de desempenho mais acentuada no período de 2011 a 2016 foi Rio Branco do Sul, que passou de 0,4732 para 0,6295. Outros municípios que apresentaram resultados evolutivos mais expressivos foram Fazenda Rio Grande, Colombo e Itaperuçu. Não obstante os indicadores de desenvolvimento municipal tenham avançado, observa-se que a disparidade entre os municípios do NUC é ainda significativa. Entre o primeiro colocado, Curitiba, e o último, Itaperuçu, há um distanciamento de quase 36 pontos percentuais.

Quadro 3 - IPDM dos municípios do NUC. Referência 2011 a 2016

\begin{tabular}{|c|c|c|c|c|c|c|}
\hline Município/Ano & $\mathbf{2 0 1 1}$ & $\mathbf{2 0 1 2}$ & $\mathbf{2 0 1 3}$ & $\mathbf{2 0 1 4}$ & $\mathbf{2 0 1 5}$ & $\mathbf{2 0 1 6}$ \\
\hline Curitiba (PR) & 0,8401 & 0,8375 & 0,8433 & 0,8492 & 0,8617 & 0,8654 \\
\hline Quatro Barras (PR) & 0,706 & 0,7283 & 0,7447 & 0,7568 & 0,7517 & 0,7631 \\
\hline Araucária (PR) & 0,7121 & 0,6947 & 0,7234 & 0,7345 & 0,7556 & 0,7564 \\
\hline Pinhais (PR) & 0,6589 & 0,6642 & 0,6971 & 0,7107 & 0,7441 & 0,7445 \\
\hline São José dos Pinhais (PR) & 0,6486 & 0,6438 & 0,6913 & 0,7164 & 0,7355 & 0,7405 \\
\hline Campo Largo (PR) & 0,666 & 0,6247 & 0,681 & 0,7061 & 0,7259 & 0,7222 \\
\hline Faz enda Rio Grande (PR) & 0,5757 & 0,5711 & 0,6164 & 0,6445 & 0,6755 & 0,6957 \\
\hline Colombo (PR) & 0,5577 & 0,5584 & 0,5923 & 0,6307 & 0,6616 & 0,6721 \\
\hline Campina Grande do Sul (PR) & 0,6132 & 0,5777 & 0,6219 & 0,6274 & 0,6494 & 0,6711 \\
\hline Campo Magro (PR) & 0,5633 & 0,5835 & 0,6332 & 0,6499 & 0,6637 & 0,6494 \\
\hline Rio Branco do Sul(PR) & 0,4732 & 0,4602 & 0,4936 & 0,5545 & 0,6117 & 0,6295 \\
\hline Piraquara (PR) & 0,5088 & 0,4787 & 0,5068 & 0,5096 & 0,5587 & 0,5683 \\
\hline A lmirante T amandaré (PR) & 0,5009 & 0,5055 & 0,5276 & 0,5312 & 0,5363 & 0,5494 \\
\hline Itap eruçu (PR) & 0,3872 & 0,3393 & 0,4149 & 0,4371 & 0,4673 & 0,508 \\
\hline
\end{tabular}

Fonte: IPARDES, 2019. Elaborado pelos autores.

Ao depletar as dimensões de renda e emprego, educação e saúde do IPDM (Quadro 4), observa-se que os níveis mais baixos de desempenho são concentrados nas duas primeiras dimensões. A média de desempenho das cidades do NUC na dimensão de renda e emprego é 
0,5416; na dimensão de educação é 0,6759; e na dimensão saúde, por sua vez, fica em 0,8257. Infere-se, então, que, na dimensão de renda e emprego, nove municípios apresentam desempenho ainda mais baixo que média do grupo, que é menor entre as dimensões. Nas demais dimensões, são cinco os municípios com desempenho abaixo da média.

Quadro 4 - Dimensões do IPDM dos municípios do NUC. Referência 2016

\begin{tabular}{|c|c|c|c|}
\hline Município/Dimensão & $\begin{array}{c}\text { Renda e emprego } \\
\text { média 0,5416 }\end{array}$ & $\begin{array}{c}\text { Educa ção } \\
\text { média 0,6759 }\end{array}$ & $\begin{array}{c}\text { S aúde } \\
\text { média 0,8257 }\end{array}$ \\
\hline Curitiba (PR) & 0,8407 & 0,8525 & 0,9029 \\
\hline Quatro Barras (PR) & 0,6917 & 0,7309 & 0,8667 \\
\hline A raucária (PR) & 0,6779 & 0,6927 & 0,8986 \\
\hline Pinhais (PR) & 0,6145 & 0,7906 & 0,8283 \\
\hline São José dos Pinhais (PR) & 0,6807 & 0,683 & 0,8579 \\
\hline Campo Largo (PR) & $\mathbf{0 , 5 2 6 6}$ & 0,7949 & 0,8451 \\
\hline Fazenda Rio Grande(PR) & $\mathbf{0 , 4 9 7 2}$ & 0,7632 & 0,8266 \\
\hline Colombo (PR) & $\mathbf{0 , 4 7 7 1}$ & 0,6791 & 0,8601 \\
\hline Campina Grande do Sul(PR) & $\mathbf{0 , 5 1 1 9}$ & 0,6982 & $\mathbf{0 , 8 0 3 3}$ \\
\hline Campo Magro(PR) & $\mathbf{0 , 4 0 4 5}$ & $\mathbf{0 , 6 7 5 8}$ & 0,8679 \\
\hline Rio Branco do Sul (PR) & $\mathbf{0 , 4 4 2 6}$ & $\mathbf{0 , 6 3 2 6}$ & $\mathbf{0 , 8 1 3 3}$ \\
\hline Piraquara (PR) & $\mathbf{0 , 3 9 8 7}$ & $\mathbf{0 , 5 3 3 7}$ & $\mathbf{0 , 7 7 2 5}$ \\
\hline Almirante Tamandaré (PR) & $\mathbf{0 , 4 0 0 8}$ & $\mathbf{0 , 4 6 4 5}$ & $\mathbf{0 , 7 8 2 9}$ \\
\hline Itaperuçu (PR) & $\mathbf{0 , 4 1 8}$ & $\mathbf{0 , 4 7 1 6}$ & $\mathbf{0 , 6 3 4 3}$ \\
\hline
\end{tabular}

Fonte: IPARDES, 2019. Elaborado pelos autores.

Em adendo à análise de desempenho no período de 2011 a 2016, é possível observar que a heterogeneidade entre os municípios do NUC é confirmada pelo Índice de Desenvolvimento Humano Municipal (IDHM) no levantamento realizado no ano de 2010 (Quadro 5), cuja média é de 0,724. Esse IDHM médio do NUC, a princípio, não destoa do índice nacional de 0,761 apurado no Relatório de Desenvolvimento Humano (IDH Global) da Organização das Nações Unidas (ONU, 2019). Pelos critérios classificativos do IDH Global ${ }^{7}$, apenas o índice de Curitiba enquadra-se como muito alto desenvolvimento humano, enquanto as demais cidades classificam-se, majoritariamente, em patamar inferior, de alto índice de desenvolvimento.

Já as cidades de Almirante Tamandaré, Rio Branco do Sul e Itaperuçu, em desvantagem em relação ao grupo, atingem apenas IDH médio de acordo com a classificação da ONU. Nestes três municípios, os dados indicam baixo desempenho no IPDM e também baixa pontuação no IDHM em relação ao grupo metropolitano. Considerando-se o número total de municípios no Estado do Paraná de 399, os dados coletados registram que as cidades de Rio Branco do Sul e Itaperuçu estão entre as 100 cidades paranaenses com o pior IDHM do estado, mesmo estando coligadas em região metropolitana com outros municípios de grande porte que, supostamente, por função de regionalidade harmoniosa, deveriam ser propulsoras de desenvolvimento integrado.

Esses dados reforçam os indicativos de que a desigualdade urbana é uma realidade evidente no Brasil e na América Latina. O crescimento urbano sem adoção de soluções integradas torna a mancha de urbanização dispersa e segregada, gerando queda na qualidade de vida e impondo desafios cada vez maiores às políticas públicas pelos impactos nos gastos públicos que se elevam para atender à população cada vez mais distante (AZEREDO; LOBO, 2004).

\footnotetext{
7 IDH baixo: inferior a 0,550; IDH médio: de 0,550 a 0,699; IDH Alto: de 0,700 a 0,799; IDH muito alto: igual o acima de
} 0,800 . 
Quadro 5 - IDHM dos municípios do NUC. Referência 2010

\begin{tabular}{|c|c|c|c|c|c|c|}
\hline Município & IDHM & $\begin{array}{l}\text { Dimensão } \\
\text { Educação }\end{array}$ & $\begin{array}{c}\text { Dimensão } \\
\text { Longevidade }\end{array}$ & $\begin{array}{c}\text { Dimensão } \\
\text { Renda }\end{array}$ & Ranking* & $\begin{array}{c}\text { Classificação } \\
\text { ONU }\end{array}$ \\
\hline Curitiba & 0,823 & 0,768 & 0,855 & 0,85 & 1 & Muito alto \\
\hline São José dos Pinhais & 0,758 & 0,678 & 0,859 & 0,749 & 21 & \multirow{10}{*}{ Alto } \\
\hline Pinhais & 0,751 & 0,666 & 0,836 & 0,761 & 29 & \\
\hline Campo Largo & 0,745 & 0,664 & 0,854 & 0,73 & 43 & \\
\hline Quatro Barras & 0,742 & 0,665 & 0,831 & 0,74 & 52 & \\
\hline A raucária & 0,74 & 0,639 & 0,852 & 0,743 & 54 & \\
\hline Colombo & 0,733 & 0,632 & 0,87 & 0,715 & 73 & \\
\hline Fazenda Rio Grande & 0,72 & 0,617 & 0,847 & 0,713 & 127 & \\
\hline Campina Grande do Sul & 0,718 & 0,605 & 0,86 & 0,712 & 136 & \\
\hline Campo Magro & 0,701 & 0,607 & 0,828 & 0,685 & 227 & \\
\hline Piraquara & 0,7 & 0,574 & 0,869 & 0,689 & 232 & \\
\hline Almirante Tamandaré & 0,699 & 0,575 & 0,84 & 0,706 & 239 & \multirow{3}{*}{ Médio } \\
\hline Rio Branco do Sul & 0,679 & 0,545 & 0,847 & 0,679 & 307 & \\
\hline Itaperuçu & 0,637 & 0,507 & 0,779 & 0,654 & 374 & \\
\hline
\end{tabular}

Fonte: IPARDES, 2010. Elaborado pelos autores.

\section{CONSIDERAÇÕES FINAIS}

A análise desenvolvida neste artigo indica que os resultados econômicos e sociais alcançados pela RMC com o atual modelo de gestão metropolitana, com hegemonia de Curitiba, não são exitosos em termos de desenvolvimento integrado dos municípios que a compõem. Isso induz à conclusão de que a inexecução de um plano integrado de desenvolvimento com governança interfederativa converte a região, que é polo de crescimento importante ao desenvolvimento nacional, em sistema que perpetua desigualdades.

Os indicadores apurados revelam que não há homogeneidade entre os municípios integrantes do NUC. Os dados demonstram, também, que os municípios com maiores percentuais de população domiciliada em área rural são aqueles com piores resultados em ambas as variáveis econômicas e sociais. O desenvolvimento que tem sido efetivamente produzido é desintegrado, concentrado em algumas regiões.

Ainda que alguns indicadores das cidades de menor capacidade econômica tenham melhorado no período de 2011 e 2016, comparativamente aos demais integrantes da região ainda é desigual a relação entre elas. A cooperação e integração não passam, de fato, de uma relação de subordinação entre os municípios, que enfraquece o elo mais fraco: a população carente. A ausência de planejamento integrado da região metropolitana sobrevaloriza o solo urbano em determinadas áreas, sobretudo na capital, causando gentrificação e deslocamento de demandas de políticas públicas da população carente para os municípios com menor potencial de atendimento. Isso acentua as desigualdades, o déficit público e a relação de dependência entre os entes federativos.

Tendo a urbanização e o desenvolvimento urbano estreita relação com o desenvolvimento econômico, é preciso que o planejamento das cidades, tanto em suas dimensões urbanas como rurais, seja usado para fornecer soluções e não acentuar os problemas. Nas regiões metropolitanas, a desarticulação ocasiona concentração de renda e investimentos, produzindo desequilíbrios econômicos e sociais e relações de subordinação entre municípios quando o objetivo seria de mútua cooperação.

O planejamento urbano carece, no entanto, de marcos institucionais eficientes. As cidades e os sistemas metropolitanos demandam governança complexa, que seja capaz de coordenar os diversos níveis de governo, federal, estadual e municipal, e engajar a sociedade civil para co-criar as soluções urbanas. O plano de desenvolvimento integrado elaborado em 2006 pela COMEC já apontava para os grandes entraves técnicos, políticos e jurídicoadministrativo na coordenação metropolitana. 
O Estatuto da Metrópole surgiu com importantes implementos exigindo a elaboração de planos de desenvolvimento urbano integrado e governança interfederativa. Porém, a aprovação da Lei Federal n ${ }^{\circ}$ 13.683, de 19 de junho de 2018, retirando a obrigatoriedade de que os estados e municípios trabalhem coletivamente na elaboração e aprovação desse plano, representou um passo atrás na superação das desigualdades entre os municípios da metrópole.

Encarar as regiões metropolitanas como uma rede de desenvolvimento e planejar-lhes de forma integrada a urbanização e o desenvolvimento econômico tornaria o processo de recuperação social e econômico mais célere pela potencialização de recursos e soluções. Para isso, como já anuncia o Estatuto da Metrópole desde 2015, é preciso união, participação social, planejamento coletivo e governança interfederativa.

\section{REFERÊNCIAS}

AZEREDO, B.; LOBO, T. O sistema municipal e o combate à pobreza no Brasil. Serie medio ambien te y desarrollo, v. 109, p. 59. Santiago de Chile: CEPAL, 2004. Disponível em: https:/ /repositorio.cepal. org/handle/11362/5650. Acesso em: 26 set. 2019.

BRASIL. Constituição da República Federativa do Brasil de 1967. Brasília: Portal da Legislação do Planalto. Disponível em http://www.planalto.gov.br/ccivil_03/constituicao/Constituicao67.htm. Acesso em: 05 out. 2019.

BRASIL. Emenda Constitucional $n^{0}$ 01, de 17 de outubro de 1969. Brasília: Portal da Legislação do Planalto. Disponível em http://www.planalto.gov.br/ccivil_03/Constituicao/Emendas/Emc_ anterior1988/emc01-69.htm. Acesso em: 05 out. 2019.

BRASIL. Constituição da República Federativa do Brasil de 1988. Brasília: Portal da Legislação do Planalto. Disponível em http://www.planalto.gov.br/ccivil_03/constituicao/constituicao.htm. Acesso em: 05 out. 2019.

BRASIL. Lei Complementar Federal $\mathrm{n}^{0}$ 14, de 08 de junho de 1973. Estabelece as regiões metropolitanas de São Paulo, Belo Horizonte, Porto Alegre, Recife, Salvador, Curitiba, Belém e Fortaleza. Brasília: Portal da Legislação do Planalto. Disponível em http://www.planalto.gov.br/ ccivil_03/leis/lcp/Lcp14.htm. Acesso em 05 out. 2019.

BRASIL. Lei Federal $\mathbf{n}^{\circ}$ 13.089, de 12 de janeiro de 2015. Institui o Estatuto da Metrópole, altera a Lei ${ }^{\circ}$ 10.257, de 10 de julho de 2001, e dá outras providências. Brasília: Portal da Legislação do Planalto. Disponível em http://www.planalto.gov.br/ccivil_03/_Ato2015-2018/2015/Lei/L13089.htm. Acesso em: 06 out. 2019.

BRASIL. Medida Provisória ${ }^{\circ}$ 818, de 11 de janeiro de 2018. Altera a Lei $n^{\circ} 13.089$, de 12 de janeiro de 2015, que institui o Estatuto da Metrópole, e a Lei $n^{\circ}$ 12.587, de 3 de janeiro de 2012, que institui as diretrizes da Política Nacional de Mobilidade Urbana. Brasília: Portal da Legislação do Planalto. Disponível em http://www.planalto.gov.br/ccivil_03/_Ato2015-2018/2018/Mpv/mpv818.htm. Acesso em: 05 out. 2019a.

BRASIL. Lei Federal $\mathbf{n}^{\circ} \mathbf{1 3 . 6 8 3}$, de 19 de junho de 2018. Altera as Leis $n^{\circ} 13.089$, de 12 de janeiro de 2015 (Estatuto da Metrópole), e 12.587, de 3 de janeiro de 2012, que institui as diretrizes da Política Nacional de Mobilidade Urbana. Brasília: Portal da Legislação do Planalto. Disponível em http://www.planalto.gov.br/ccivil_03/_Ato2015-2018/2018/Lei/L13683.htm. Acesso em: 05 out. $2019 b$.

BRASIL. Relatório Anual de Avaliação do Plano Plurianual, Ano-base 2017. Brasília: Ministério da Economia, Planejamento, Desenvolvimento e Gestão, 2018. Disponível em: https://www.gov.br/economia/pt-br/arquivos/planejamento/arquivos-e-imagens / secretarias/arquivo/spi-1/ppa-2016-2019/relatorio_avaliacao_ppa_2017_volume_2.pdf/view Acesso em: $20 \mathrm{dez} .2019 \mathrm{c}$. 
CEPAL - COMISSÃO ECONÔMICA PARA A AMERICA LATINA E O CARIBE. Plan de acción regional para implementación de la nueva agenda urbana en América Latina y el Caribe. 2016 - 2036. Santiago: Organização das Nações Unidas, 2016. Disponível em: https://repositorio.cepal. org/bitstream/handle/11362/42144/2/S1800033_es.pdf. Acesso em:12 set. 2019.

COMEC - COORDENAÇÃO DA REGIÃO METROPOLITANA DE CURITIBA. Plano de desenvolvimento integrado da região metropolitana de Curitiba: propostas de ordenamento territorial e novo arranjo institucional. Curitiba: COMEC, 2006. Disponível em: http:// www.comec.pr.gov.br/Pagina/PDI-Plano-de-Desenvolvimento-Integrado-da-RMC-2006. Acesso em: 6 out. 2019.

CRESWELL, J. W. Projeto de Pesquisa: métodos qualitativos, quantitativos e mistos. Porto Alegre: Artmed, 2010.

CURITIBA. Lei Municipal $\mathbf{n}^{\circ}$ 14.771, de 17 de dezembro de 2015. Dispõe sobre a revisão do Plano Diretor de Curitiba de acordo com o disposto no art. $40, \S 3^{\circ}$, do Estatuto da Cidade, para orientação e controle do desenvolvimento integrado do município. Curitiba: Câmara Municipal, [2015]. Disponível em https://leismunicipais.com.br/a/pr/c/curitiba/lei-ordinaria/2015/1477/14771/ lei-ordinaria-n-14771-2015-dispoe-sobre-a-revisao-do-plano-diretor-de-curitiba-de-acordo-com-odisposto-no-art-40-3-do-estatuto-da-cidade-para-orientacao-e-controle-do-desenvolvimentointegrado-do-municipio. Acesso em: 05 out. 2019.

CURITIBA. Lei Municipal $n^{0}$ 15.511, de 10 de outubro de 2019. Dispõe sobre o zoneamento, uso e ocupação do solo do Município de Curitiba e dá outras providências. Curitiba: Câmara Municipal, [2019]. Disponível em: https://leismunicipais.com.br/a/pr/c/curitiba/lei-ordinaria/2019/1551/ 15511/lei-ordinaria-n-15511-2019-dispoe-sobre-o-zoneamento-uso-e-ocupacao-do-solo-nomunicipio-de-curitiba-e-da-outras-providencias. Acesso em: 12 dez. 2019.

FLORIDA, R. Cities are the engines of global progress: they can act as economic engines for entire countries. Poverty in focus. A new urban paradigm: pathways to sustainable development. The International Policy Centre for Inclusive Growth, v. 13, n. 3, p. 16-17. Brasília: United Nations Development Programme, 2016. Disponível em: http://www.ipc-undp.org/pub/eng/PIF37_ A_new_urban_paradigm_pathways_to_sustainable_development.pdf. Acesso em: 17 set. 2019.

FREITAS-FIRKOWSKI, O. L. C. Reflexões sobre o estatuto das metrópoles e plano de desenvolvimento metropolitano. Instituto Municipal de Administração Pública (IMAP). Estado, planejamento e administração pública. Curitiba: IMAP, 2015. p. 5-19

GODOY, A. S. Pesquisa qualitativa: tipos fundamentais. Revista de Administração de Empresas, São Paulo, v. 35, n.3, 1995.

GONZALEZ, L. M. C. Ciudad y territorio en América Latina. Bases para una teoría multicéntrica, heterodoxa y pluralista. Santiago de Chile: CEPAL, 2017. Disponível em: https://www.cepal.org/ptbr/node/43298. Acesso em: 26 set. 2019.

GORSDORF, L. F. A dimensão metropolitana nos planos diretores da região metropolitana de Curitiba. In: MOURA, R.; FIRKOWSKI, O. C. F. (org.). Dinâmicas intrametropolitanas e produção do espaço na região metropolitana de Curitiba. Rio de Janeiro: Observatório das Metrópoles: Observatório de Políticas Públicas Paraná; Curitiba: Letra Letra Capital editora, 2009.

IBGE - INSTITUTO BRASILEIRO DE GEOGRAFIA E ESTATÍSTICA. Tabela 1301 - Área e Densidade demográfica da unidade territorial. SIDRA. Banco de Tabelas Estatísticas, 2010. Disponível em: https:/ / sidra.ibge.gov.br/Tabela/1301\#resultado. Acesso em: 5 out. 2019a.

IBGE - INSTITUTO BRASILEIRO DE GEOGRAFIA E ESTATÍSTICA. Tabela 608 - População residente, por situação do domicílio e sexo - Sinopse. SIDRA. Banco de Tabelas Estatísticas: 2010. Disponível em: https:/ / sidra.ibge.gov.br/Tabela/608\#resultado. Acesso em:14 dez. 2019b.

IBGE - INSTITUTO BRASILEIRO DE GEOGRAFIA E ESTATÍSTICA. Tabela 5938 - Produto interno bruto a preços correntes, impostos, líquidos de subsídios, sobre produtos a preços correntes e valor adicionado bruto a preços correntes total e por atividade econômica, e respectivas participações - 
Referência 2010. SIDRA. Banco de Tabelas Estatísticas, [s.d]. Disponível em https://sidra. ibge.gov.br/tabela/5938\#resultado. Acesso em 05 out. 2019c.

IBGE - INSTITUTO BRASILEIRO DE GEOGRAFIA E ESTATÍSTICA. Tabela 6579 - População residente estimada. Referência 2019. SIDRA. Banco de Tabelas Estatísticas, 2019. Disponível em https:// sidra.ibge.gov.br/tabela/6579\#resultado. Acesso em 04 set. 2019.

IPARDES - INSTITUTO PARANAENSE DE DESENVOLVIMENTO ECONÔMICO E SOCIAL. Índice de Desempenho Municipal - Referência 2010 a 2016. Curitiba: IPARDES, 2019. Disponível em: http:/ / www.ipardes.pr.gov.br/Pagina/Indice-Ipardes-de-Desempenho-Municipal-0. Acesso em: 8 out. 2020.

IPARDES - IPARDES - INSTITUTO PARANAENSE DE DESENVOLVIMENTO ECONÔMICO E SOCIAL. IDH-M - Índice de Desenvolvimento Humano Municipal - Referência 1991, 2000, 2010. Curitiba: IPARDES, 2010. Disponível em: http://www.ipardes.pr.gov.br/Pagina/IndicadoresSociais. Acesso em: 8 out. 2020.

KAZTMAN, R. La dimensión espacial en las políticas de superación de la pobreza urbana. Serie medio ambiente y desarrollo, v. 59, p. 44. Santiago de Chile: CEPAL, 2003. Disponível em: https:// repositorio.cepal.org/bitstream/handle/11362/5761/S0210799.pdf?sequence=1. Acesso em: 17 set. 2019.

LIMA, J. F.; BIDARRA, B. S. Concentração e desigualdade na Região Metropolitana de Curitiba. Revista Brasileira de Gestão Urbana, [S.1.], v. 11, maio 2019. ISSN 2175-3369. Disponível em: https:// periodicos.pucpr.br/index.php/Urbe/article/view/24155. Acesso em:19 dez. 2019.

MARCONI, M. A.; LAKATOS, E. M. Fundamentos de metodologia científica. 8. ed. São Paulo: Atlas, 2017.

ONU - ORGANIZAÇÃO DAS NAÇÕES UNIDAS. Human development report. United Nations Development Programme, 2019. Disponível em: http://hdr.undp.org/sites/default/files/hdr_ 2019_overview_-_english.pdf. Acesso em 19 dez. 2019.

PARANÁ. Lei Estadual $\mathrm{n}^{0}$ 6.517, de 02 de janeiro de 1974. Institui a Coordenação da Região Metropolitana de Curitiba - COMEC. Curitiba: Casa Civil, Sistema Estadual de Legislação. Disponível em: https://www.legislacao.pr.gov.br/legislacao/pesquisarAto.do?action=exibir\&codAto=8910 \&indice $=1 \&$ totalRegistros $=1 \& \mathrm{dt}=8.9 .2019 .19 .54 .38 .501$. Acesso em: 05 out. 2019 .

PARANÁ. Lei Estadual $n^{0}$ 11.027, de 29 de dezembro de 1994. Transforma a Coordenação da Região Metropolitana de Curitiba - COMEC em autarquia e adota outras providência. Curitiba: Casa Civil, Sistema Estadual de Legislação. Disponível em: https://www.legislacao.pr.gov.br/legislacao/ pesquisarAto.do?action $=$ exibir\&codAto $=4489 \&$ indice $=1 \&$ totalRegistros $=1 \& \mathrm{dt}=8.9 .2019 .19 .56 .7 .933$. Acesso em: 05 out. 2019.

PARANÁ. Lei Estadual $\mathrm{n}^{0}$ 11.096, de 16 de maio de 1995. Altera o parágrafo único, do art. $2^{\circ}$, da Lei ${ }^{\circ}$ 11.027, de 29 de dezembro de 1994. Curitiba: Casa Civil, Sistema Estadual de Legislação. Disponível em: https:/ / www.legislacao.pr.gov.br/legislacao/pesquisarAto.do?action= exibir\&codAto $=4957 \&$ indice $=1 \&$ totalRegistros $=1 \& \mathrm{dt}=8.9 .2019 .19 .57 .19 .572$. Acesso em: 05 de out. 2019 .

PARANÁ. Lei Estadual $\mathbf{n}^{0}$ 12.125, de 22 de abril de 1998. Dá nova redação ao parágrafo único, do art. $2^{\circ}$, da Lei no 11.027, de 29.12.94. Curitiba: Casa Civil, Sistema Estadual de Legislação. Disponível em: https:/ / www.legislacao.pr.gov.br/legislacao/ pesquisarAto.do?action=exibir\&codAto=2366\&indic $\mathrm{e}=1 \&$ totalRegistros $=1 \& \mathrm{dt}=8.9 .2019 .19 .59 .6 .214$. Acesso em: 05 out. 2019.

PARANÁ. Lei Estadual $\mathbf{n}^{0}$ 13.512, de 21 de janeiro de 2002. Dá nova redação ao parágrafo único do Art. $2^{\circ}$, da Lei n ${ }^{\circ} 11.027$, de 29 de dezembro de 1994. (COMEC). Curitiba: Casa Civil, Sistema Estadual de Legislação. Disponível em: https://www.legislacao.pr.gov.br/legislacao/pesquisar Ato.do? action $=$ exibir\&codAto $=3534 \&$ indice $=1 \&$ totalRegistros $=1 \& \mathrm{dt}=8 \cdot 9 \cdot 2019.20 \cdot 0.28 .927$. Acesso em: 05 out. 2019. 
PARANÁ. Lei Complementar Estadual $\mathrm{n}^{0}$ 139, 09 de dezembro de 2011. Altera o parágrafo único do art. $2^{\circ}$, da Lei $n^{\circ} 11.027$, de 29 de dezembro de 1994, (COMEC), incluindo os Municípios de Piên, Campo do Tenente e Rio Negro. Curitiba: Casa Civil, Sistema Estadual de Legislação. Disponível em: https://www.legislacao.pr.gov.br/legislacao/ pesquisarAto.do?action=exibir\&codAto $=62625 \&$ indi $\mathrm{ce}=1 \&$ totalRegistros $=1 \& \mathrm{dt}=8.9 \cdot 2019.20 .1 .40 .940$. Acesso em: 05 out 2019.

PARANÁ. Decreto Estadual $\mathbf{n}^{0}$ 6.384, de 04 de abril de 2006. Passa a vincular a Coordenação da Região Metropolitana de Curitiba - COMEC à Secretaria de Estado do Desenvolvimento Urbano SEDU. Curitiba: Casa Civil, Sistema Estadual de Legislação. Disponível em em: https://www. legislacao.pr.gov.br/legislacao/pesquisarAto.do?action=exibir\&codAto $=42426 \&$ indice $=1 \&$ totalReg istros $=6 \& d t=8 \cdot 9 \cdot 2019 \cdot 20.3 \cdot 27.774$. Acesso em: 05 out. 2019 .

SANFELICI, D. A centralidade das aglomerações metropolitanas na economia globalizada: fundamentos econômicos e possibilidades políticas. Cadernos Metrópole, v. 37, n. 37, p. 623-646, 28 out. 2016. Disponível em: http:/ / dx.. Acesso em: 12 mar. 2021.

SOUZA, C. Regiões metropolitanas: condicionantes do regime político. Lua Nova: Revista de Cultura e Política, n. 59, p. 137-158, 2003. Disponível em: http://www.scielo.br/scielo.php?script=sci_ arttext\&pid=S0102-64452003000200007\&lng=en\&nrm=iso\&tlng=pt. Acesso em:12 mar. 2021.

\section{INFORMAÇÕES DOS AUTORES}

\section{Priscila Perelles}

Mestranda em Planejamento e Governança Pública pela Universidade Tecnológica Federal do Paraná-UTFPR.

E-mail:priperelles@gmail.com

Orcid:https:/ / orcid.org/0000-0001-8650-5576

Lattes: http:/ / lattes.cnpq.br/3199683841447186

\section{Ivan Carlos Vicenti}

Professor da Universidade Tecnológica Federal do Paraná (UTFPR), atuando no Mestrado e Doutorado Profissional em Planejamento e Governança Pública. Doutor em Administração pela Universidade de São Paulo (USP) e Mestre em Administração pela Universidade Federal do Rio Grande doSul - (UFRGS)

E-mail:vicentin@utfpr.edu.br

Orcid: https:/ / orcid.org/0000-0002-7081-4005

Lattes: http:/ / lattes.cnpq.br/ 6534550312384359

\section{Maria Meza}

Coordenadora do Curso de Especialização em Gestão Pública Municipal e Professora da Universidade Tecnológica Federal do Paraná (UTFPR), atuando no Mestrado e Doutorado Profissional em Planejamento e Governança Pública e no Mestrado em Administração. É também Diretora de Relações Empresariais e Comunitárias da UTFPR. Doutora em Desenvolvimento Econômico pela Universidade Federal do Paraná (UFPR), Tem como foco de pesquisa políticas públicas; ciência, tecnologia e desenvolvimento regional e empreendedorismo público.

E-mail:malumeza@utfpr.edu.br

Orcid: https:/ / orcid.org/0000-0002-1875-5140

Lattes:http:/ / lattes.cnpq.br/3634990002513047

Recebido em: 08/10/2020

Aceito em: 07/04/2021 